\title{
Serious Game for Leadership Skills in the Learning Organization Training
}

\author{
Basuki Wibawa, Pramis B. Wibawa
}

\begin{abstract}
This paper examines the potential of Serious Games (SG) to support leadership skills improvement training in learning organizations for higher education students. It highlights the main requirements for training and presents a variety of table templates, based on advanced models for leadership training, which have been used to examine the most suitable SG and determine the most appropriate combination to be used in training by considering targeted competencies and skills, uses and effectiveness learning. SG made to cater education and training purposes, by participating in $S G$, participants able to acquire and retain knowledge more effectively rather than using conventional methods. Consecutively, there is an Immersive Virtual Really (IVR); a technology that can bolster the engaging capabilities of SG. By combining IVR, participants can be completely immersed in virtual environments which offers greater engagement and perception. The combination resulted in participants' encouragement to preserve knowledge longer than any conventional method due to stronger emotional attachment along with physiological arousal. There is an augmenting number investigating the combination of SG and IVR for the purpose of leadership training and behavioral assessment. Hence, a systematic understanding of the development of SG and how it is being implemented for leadership training and research is essential. On this regard, the authors conducted a systematic literature review in five stages, namely; formulation of research problems, identification of relevant prior studies, quality assessment of the studies, summarizing evidence and end with findings interpretation.
\end{abstract}

Finally, this paper introduces a systematic literature review regarding $S G$ oriented toward building leadership processes, critically analyzes the situation, and the direction of future research for the development of $S G$ is more effective for leadership training.

Index Terms: Leadership Skills, Learning Organization, Serious Games, Systematic Review and Training.

\section{INTRODUCTION}

Serious Game (SG) have appealed attention on pedagogical research in the recent years. By participating in SG, participants able to achieve and preserve knowledge effectively rather than using conventional learning approach. Consecutively, there is an Immersive Virtual Really (IVR); a technology that can bolster the engaging capabilities of SG. By combining IVR, participants can be completely immersed in virtual environments which offers greater engagement and

Revised Manuscript Received on 14 September, 2019.

Basuki Wibawa, Universitas Negeri Jakarta, Jl. Rawamangun Muka, RT011/RW014 Jakarta 13220.bwibawa@unj.ac.id

Pramis B.Wibawa, Universitas Brawijaya, J1. Abdul Muis No. 52 RT002/ RW003 Jakarta 10160, pramiswibawa@student.ub.ac.id, benetiara@hotmail.com perception ${ }^{[8]}$. The combination resulted in participants' encouragement to preserve knowledge longer than any conventional method due to, stronger emotional attachment along with physiological arousal ${ }^{[3]}$. Hence, with an augmenting number investigating the aforementioned combination, a systematic understanding of the development of SG and how it is being implemented for leadership training and research is essential. On this regard, the authors conducted a systematic literature review in five stages, namely; formulation of research problems, identification of relevant prior studies, quality assessment of the studies, summarizing evidence and end with findings interpretation. This study introduces a systematic literature review on the potentials of serious game (SG) in building leadership skills in the learning organization training; how is a conceptual framework to guide the development and implementation of such SG is offered for leadership skills in the learning organization training?

\section{THEORETICAL REVIEW}

\section{A. Leadership Skills}

In general, the articles and books of leadership state leadership as influencing the actions of others. Ken Blanchard ${ }^{[1]}$ defined leadership as "in any situation in which someone is trying to influence the behavior of another individual or group, leadership is occurring." In the recent year, leadership is described as "capacity to influence others by unleashing their power and potential to impact the greater good. ${ }^{[1] "}$ There are five levels of leaders embraced by organizations namely as: Highly Capable Individual (level 1): able to provide productive contributions through managing talent, knowledge and good working habits; Contributing Team Member (level 2): provides individual capabilities to the common goals and works comfortably in a group setting; Competent Manager (level 3): effectively and efficiently coordinates people and resources to pursue desire outcomes; Effective Leader (level 4): promotes dynamic pursuit of version and stimulates higher performance standards; Executive (level 5): develops long-term greatness through an unusual blend of personal modesty and professional great-will. Their resolve is to do whatever is needed to make the organization "great."

There have been three principal leadership phases since the Industrial Revolution and edging into a fourth Leadership $\quad 1.0 \quad$ was charisma-led. Charisma is defined as "certain quality of an individual personality by

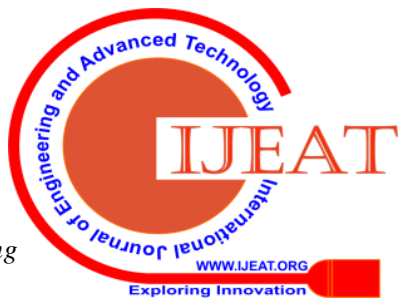




\section{Serious Game for Leadership Skills in the Learning Organization Training}

virtue of which he is set apart from ordinary men and treated as endowed with supernatural, superhuman, or at least specifically exceptional powers or qualities ${ }^{[14]}$." Leadership 2.0 was the era of scientific management. Daniel McCallum [15] develop the first organizational chart and produced general principles of management that supported top-down command and control leadership. James MacGregor Burns [16] described transformational leaderships as a moral dimension where 'the transforming leader looks for potential motives in followers and engages the full person of the follower," resulted in a relationship of mutual stimulation and advancement that alters followers into leaders and may convert leaders into moral agents. The future leadership is no longer about control, positional power, status and rank
Decisions are made through ideas and innovation which will come through open collaboration and collaborative networks.

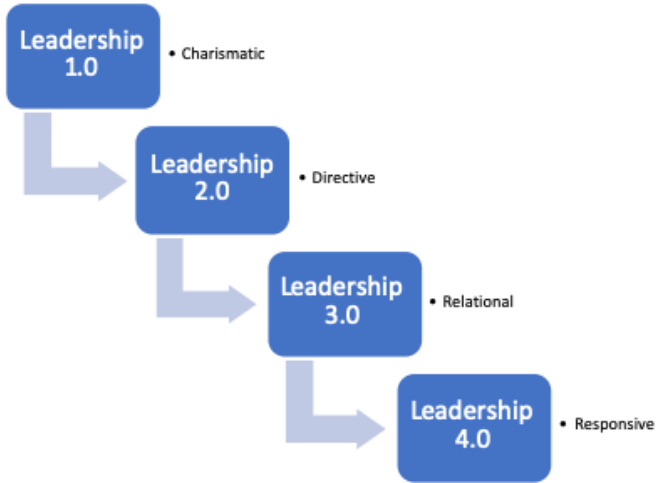

Fig 1. Four Leadership phases

\begin{tabular}{|c|c|c|c|}
\hline Leadership Theory & Date & & Major publications \\
\hline Swarm Leadership & 2017 & & Swarm Leadership and the Collective Mind by Peter Gloor \\
\hline Responsive Leadership & 2017 & ent & 2017 World Econmic forum Key theme at Davos \\
\hline Holacracy & 2015 & as & Holacracy: the New Mansegement System for a Rapidly Chansine World by Brian Robertson \\
\hline Cornectivism & 2005 & & Connectivism: Learning as Network-Creation by George Siemens \\
\hline Shared leadership & 2003 & & Shared Leadership: Reframing the Hous and Whys of leadership by Craic Pearce and lav Conger \\
\hline Distributed Leadership & 2002 & & Distributed leadership as a Unit of Analyils by Peter Gronn \\
\hline Collaborative Leadership & 1994 & & Collaborative Advantage by Rocabeth Moss Kanter \\
\hline Adaptive Leadershio & 1994 & & Leadership Without Easy Answers by Ronald Heifetz \\
\hline Transformational Leadership & 1990 & & The Leadership Challenge by iames Kouzes and Barry Posner \\
\hline Constructivism & 1987 & & The Tree of Knowledge by Humberto Maturans and Francisco Varels \\
\hline Constructivism & 1987 & & The construction of knowledge by Ernst von Clasersfeld \\
\hline Trandiormational leadership & 1985 & & Leadership and Performance Beyond Expectations by Bernard Eass \\
\hline Constructivism/cognitivism & 1983 & & Frames of Mind by Howard Gardner \\
\hline Servant Leadership & 1977 & 4 & Sevant Leadership by Robert Greenleaf \\
\hline Transformational leadership & 1978 & vanis & Leadership by lames MacGregor Burns \\
\hline Instrumental Leadership & 1975 & & Path-Goal Theory of Leadership by Robert House and Terrence Mitchell \\
\hline Transactional Leadership & 1975 & & A Vertical Dyad Uniage Approach to Leadership Within Formal Ortaniastions by Fred Danseresu et al. \\
\hline Situational Leadership & 1973 & & Leadership and Decision-Naking by Victor Vroom, and Philip Yetton \\
\hline Situational Leadership & 1969 & & Management of Organizational Behavior by P. Mersey and K Bianchard \\
\hline Coenitivism & 1967 & & Cognitive Psycholorv by Uiric Neisser \\
\hline Contincency theory & 1964 & & A Theory of Leadership Effectiveness by Fred Fiedier \\
\hline Cognitivism & 1963 & & Social Learnine and Personality Development by Albert Bandura and Richard H. Walters \\
\hline Cognitivism/Constructivism & 1956 & & A Study of Thinking by lerome Bruner \\
\hline Behaviourism & 1950 & & Michigan State University Leadership Studes \\
\hline Coentivism & 1948 & & Cognitive Mags in Rats and Men by Edward Tolman \\
\hline Cybernetics & 1948 & & Cybernetics: or Control and Communication in the Animal and the Machine by Norbert Wiener \\
\hline Behaviourism & 1945 & & Ohio State Leadership Studies \\
\hline Behoviourism/Cognitvism & 1943 & & A Theory of Human Motivation by A. H. Masiow \\
\hline Leadership Stvies & 1939 & & $\begin{array}{l}\text { Patterns of Aavessive Behavior inteaperimentaly Created 'Social Climates' by Lewin, Uppitt and } \\
\text { White }\end{array}$ \\
\hline Behaviourism & 1938 & & The Behavior of Organisms by BF Skimer \\
\hline Trait Theory & 1937 & & Personality. a Psychological interpretation by GW Allport and Ross Stapner \\
\hline Sclentific Management & 1920 & & Economy and Society. An Outine of Interpretive Sociology by Max Weber \\
\hline Scientific Management & 1916 & & General and industrial Management by Henri Fayd \\
\hline Scientific Management & 1911 & & The Principles of Scientific Management by Frederick Taylor \\
\hline Behoviourism & 2898 & & Animal Intelligence: An Experimental Study of the Associate Processes in Animals by E. L. Thorndike \\
\hline Behaviourism & 1887 & & The work of the digestive glands by han Paviov \\
\hline Scientific Management & 1856 & uneme & - Report of the Superintendent of the New York and Erie Ralload to the Stockholders by Daniel Mccallum \\
\hline Great Man Theory & 1841 & & On Heroes, Hero-Worship, and The Heroic in History by Thomas Carlyle \\
\hline
\end{tabular}

Fig 2 Leadership Timeline (Richard Kelly, 2019)

\section{A. Serious Games}

In recent years, Serious Game (SG) have attracted researchers' attention and becoming more popular as it becomes a method of transfer knowledge along with popular training and behavior analysis tool ${ }^{[6]}$. The term serious game represents a video game whose main purposes are advertising, analyzing, education, exploring, simulation, socializing and training rather than pure entertainment. It inherits the interface and gameplay characteristics from its counterpart, yet mainly focus on learning or training and the lessons learnt from the game are expected to be used in real-life working environments. Cook et al ${ }^{[5]}$ stated by providing a realistic environment in a serious game, learning process can advance from knowledge acquisition towards skills development to

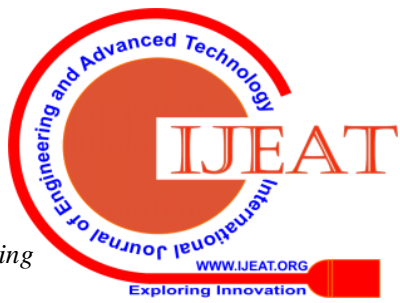


recognition, analyzation, selection and application of knowledge into different situations. Serious game is answering the need for specialised training in order to enhance the realistic experience faced by the users, its combination of design, gaming technology, and process to the solutions faced by business and other organisations ${ }^{[2,13]}$. There are four main principals components of serious game; rules and gameplay, challenges, interaction modes, and objectives. The game objectives could be both explicit and implicit. Explicit as its stated and implicit goals as it includes improving leadership skills, gaining knowledge through the game and acquiring experiences.

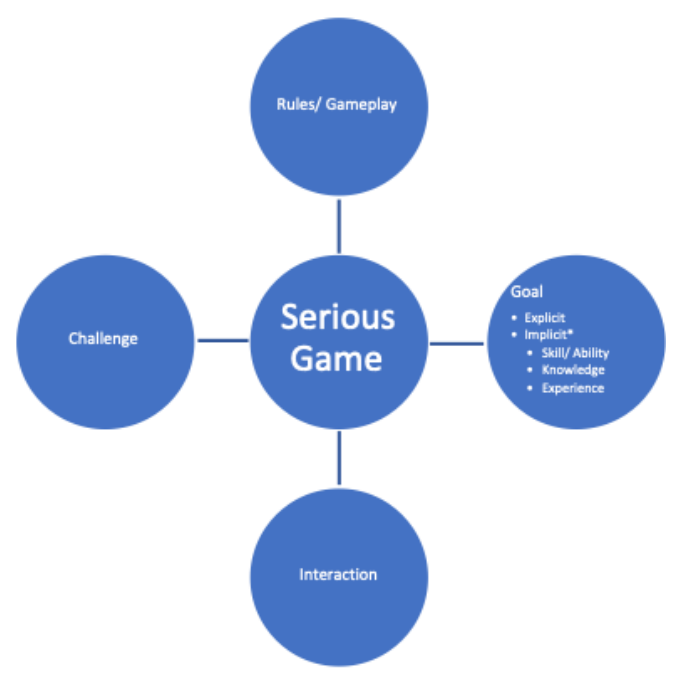

Fig 3 Components of Serious Game

Its gaming structure allows tracking participants' decisions and recording their behavior during a game. By collecting and analyzing those behavioral data, it reveals behavioral motivation, validate behavioral models, explore decision-making, recognize behavioral patterns and do assessment of the responses under in varied controlled conditions. Hence, serious game is prospective to offer the understanding of behavioral patterns and behavior changes beyond educational and training aspects.

\section{1) Serious Game Scenario Development}

The scenario development of a serious game (SG) is considered complex as it does not have a linear storyline, yet it rather exists with a dynamic metaplot with the participating player in the unfolding sequence of problems and the interactions made within the game influence the outcomes. As technology advances it progressively possible to create a game engine allowing more branches of flexibles rules that enable higher order learning by integrating complex underlying models that allow for an untold number of results. Such flexibility offers an advantage in which each time the participant plays the game, the experience is unique due to the degree of flexibility rule structures offers them to explore the game interface, test hypotheses and reach goals in different and unanticipated manners.

\section{a) Immersive virtual reality (IVR)}

LaValle ${ }^{[9]}$ defined immersive virtual reality as "inducing targeted behavior in an organism by using artificial sensory stimulation, while the organism has little or no awareness of the interference." Regarding to this definition, participants will be able to feel the sensation that physically they are inside the controlled virtual environment. The artificially-made and stimulated environment may become realistic increasing the difficulty level for participants to differentiate between the virtual and real world ${ }^{[9]}$. Krokos et

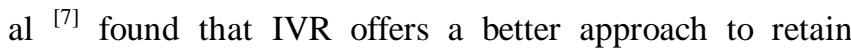
knowledge compared to non-IVR environment due to the combination of IVR in SG brings a higher degree of engagement along with participants when compared to non-IVR-SG ${ }^{[8]}$.

\section{2) Serious Game Engine Development}

Dhaliwal and Benbasat (1996) identified that the systems were firstly used in the mid-1960s when AI research focused on defining problems that could be explained using static underlying human expertise. The new systems connect both video game engines with autonomous human expert knowledge bases, resulting to "expert system." Figure 4 exhibits the framework of the serious game.

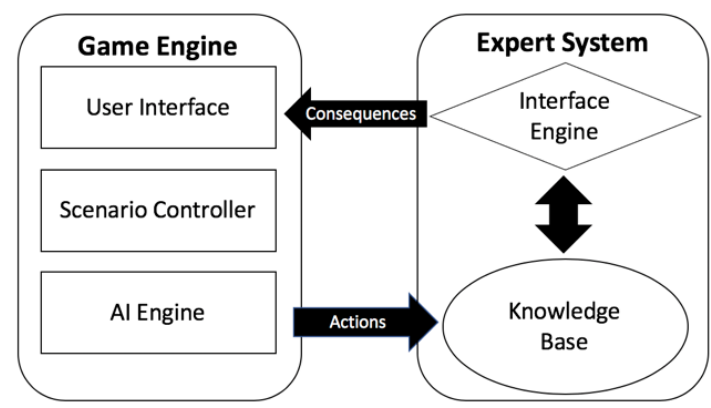

Fig 4 Serious Game Framework

The Expert System

1. The knowledge base (KB) comprises the domain expertise and knowledge, represents in the form of facts and rules that the expert system uses to make determinations,

2. The inference engine reads and activates the rules in the knowledge base whenever the conditions are satisfied, deriving recommendations from the knowledge base and problem-specific data from the dynamic facts base and thus resulting in new facts.

The Game Engine

1. The user interface controls the dialog between the user and the system and allows the student to interact in a virtual 3D environment,

2. The purpose of the scenario controller is to initialize the game session; defining its objectives; and updating the objectives when they have been completed or become irrelevant,.

3. The AI game engine reads the consequences of the rules activated by the expert system. Throughout the scenario, the system considers the time required for an expected response and adjusts it to the evolution of the scenario accordingly. 


\section{Serious Game for Leadership Skills in the Learning Organization Training}

Since there is a certain level of subjectivity evaluation for problem-solving and the usage of higher-order thinking skills, the final analysis of the participants' reasoning skills will be evaluated outside the serious game environment due to "the performance assessment using scoring rubrics that may describe different level of proficiency is considered unsuitable for computer games ${ }^{[11]}$."

\section{METHODOLOGY}

The methodology used in this study is a systematic of literature review. The systematic literature review was conducted in five stages: formulating the research problems, identifying relevant work, assessing the quality of studies, summarizing the evidence, and interpreting the findings.

\section{RESULTS AND DISCUSSIONS}

\section{A. Formulating the research problems.}

Rüppel and Schatz ${ }^{[13]}$ elaborated three interdependent worlds that need to be balanced during the design process of a serious game: reality (how the game is connected to the physical world), significance (what value needs to be achieved), and performance (how to create playful activities). The authors then observed the three principal aspects. The observation allowed us answering two main research questions in order to get an in-dept understanding along with the formulation of eleven sub-questions.

In summary, there are two type of impacts of training and research IVR-SG; pedagogical impact and behavioral impact [10]. Sub-question 1 and sub-question 2 were formulated to discover the pedagogical impact, while sub-question 3 and sub-question 4 were intended for behavioral impact. Sub-question 5 was formulated to explain the measurement of participations' experience during a session of serious game, followed by sub-question 6 up to sub-question 11 were formulated to explore specific details of various systems, including the teaching methods, navigation solutions, sense stimulation, narrative methods, non-playable characters, and hazard simulation.

\begin{tabular}{|c|c|c|}
\hline $\begin{array}{l}\text { Main Research } \\
\text { Questions (MQ) }\end{array}$ & Sub-questions (SQ) & Assessed Aspects \\
\hline $\begin{array}{l}\text { MQ1: What are the } \\
\text { outcomes and } \\
\text { measures for } \\
\text { implementing IVR } \\
\text { SGs in evacuation } \\
\text { study? }\end{array}$ & $\begin{array}{l}\text { SQ1: What are the } \\
\text { learning } \\
\text { outcomes? SQ2: } \\
\text { What are the } \\
\text { learning } \\
\text { measures? SQ3: } \\
\text { What are the } \\
\text { behavior } \\
\text { outcomes? SQ4: } \\
\text { What are the } \\
\text { behavior } \\
\text { measures? SQ5: } \\
\text { How to evaluate the } \\
\text { participation } \\
\text { experience? }\end{array}$ & $\begin{array}{l}\text { Meaning: } \\
\text { Pedagogical } \\
\text { impact } \\
\text { Meaning: } \\
\text { Behavioral impact } \\
\text { Play: Participation } \\
\text { experience Play: } \\
\text { Hardware and } \\
\text { software system } \\
\text { Reality: Software } \\
\text { system }\end{array}$ \\
\hline
\end{tabular}

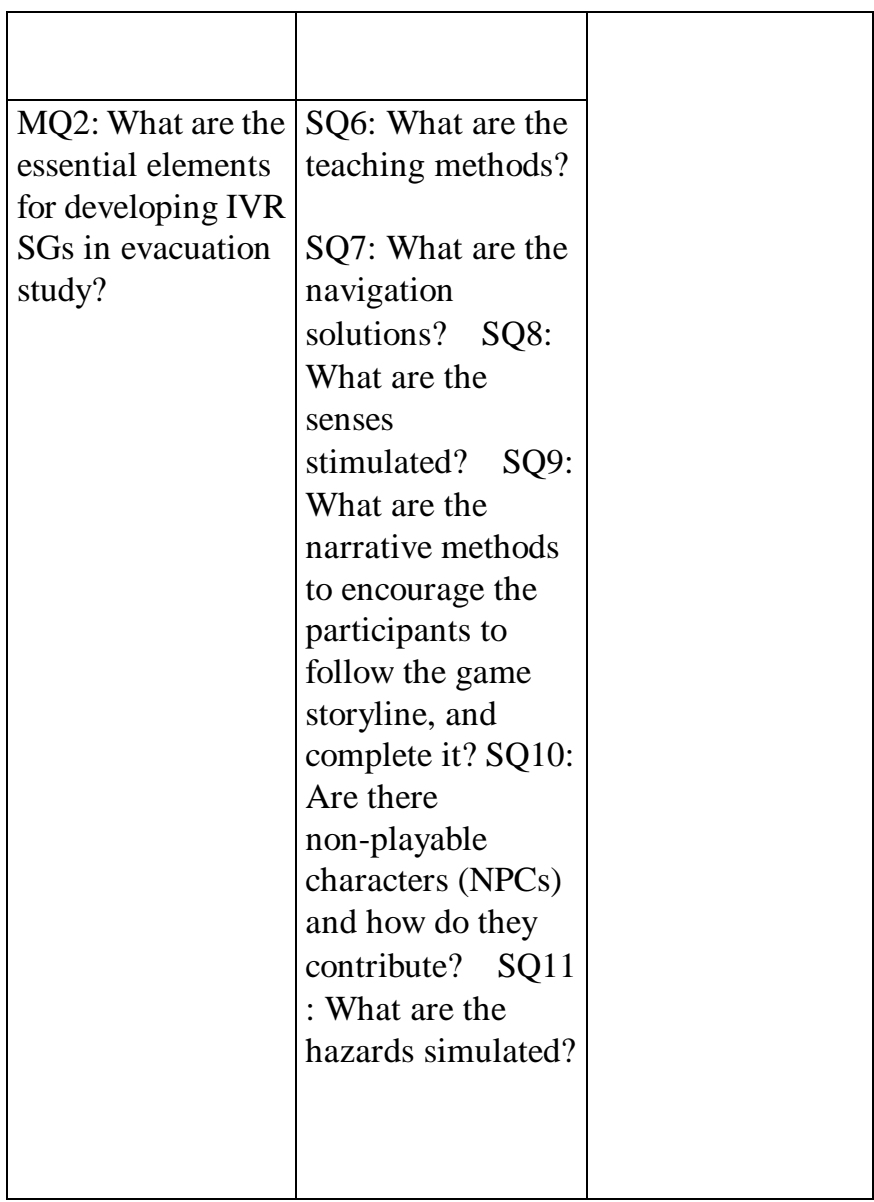

\section{B. Identifying the relevant work}

This particular step includes three main concepts; immersive virtual reality, serious games (SG), and evacuation training and research. Eligible papers included in the systematic literature review were collected from journals and conference proceedings.

\section{Assessing the quality of studies}

Once the identification of eligible paper was done, it followed by a scoring process in order to evaluate the papers quality. Each paper was scored based on the three assessment questions based on the quality assessment approach ${ }^{[4]}$; (a) How appropriate is the prototype design in addressing the questions of this review? (b) How appropriate are the methods and analysis for addressing the question of this review? (c) How relevant is the focus of the study for addressing the questions of this review?

Each dimension have a score ranged from 1 to 3 , in which 1 have the lowest quality, 2 means medium quality and 3 possess the highest quality. The three dimensions' scores were summed to obtain a total score for each paper.

\section{Summarizing the evidence}

Then, the qualified prior papers were analyzed and coded using a data extraction spreadsheet which included the aforementioned research factors and research questions resulted in two types of identified outcomes namely pedagogical outcomes and behavioral outcomes. 


\section{E. Interpreting the findings}

On the regard of analyzed data in the prior step, the authors synthesized numerous aspects and factors which have influences on the development and implementation of an IVR-SG leadership training into a conceptual framework shown in Fig. 5.

IVR-SG resulted diverse outcomes for the behavioral impact namely behavior compliance, behavior recognition and behavior validation. Further, there are important measures for the gaming development process are needed to be added into IVR-SG in order to evaluate and trace behavior and record participants' data.

Another important concern is the selection of IVR equipment. Head-mounted display (HMD) and projection-based display (PBD) were classified in the study. Each need distinctive navigation solutions, which are the crucial parts of IVR-SG.

On the development process, several elements in the conceptual framework are taken into consideration by developers in order to reach high-quality IVR-SG. For instance, stimulated hazards; static hazards and dynamic hazards. Static hazards influence game narrative particularly on the surrounding-drive approach by creating hazardous area in which give participants limited moving option. Other than static hazard, there is dynamic hazards which rather flexible varying on training purposes and the background of participants. Participants must feel being physically within a virtual world to reduce unrealistic behavior, hence sense stimulation is principally depending on the equipment availability. Non-playable characters (NPCs) are also considered as a crucial factor of IVR-SG due to their capability in increasing the realism of IVR-SG and aptitude to interact with participants in order to reach research objectives.

Once the development process is completed, the expected research objectives shall be measured during the implementation phase in order to confirm the effectiveness of IVR-SG along with participant' experience to achieve strong evidence in supporting the results and providing feedback to evaluate the usability of IVR-SG. If the end-results are not desirable, there must be improvements on the IVR-SG in accordance with the measured results until the results meet the expectations. Once the improvement is implemented, a final product of IVR-SG is considered completed which it now able to deliver expected research objects that meet research requirements.

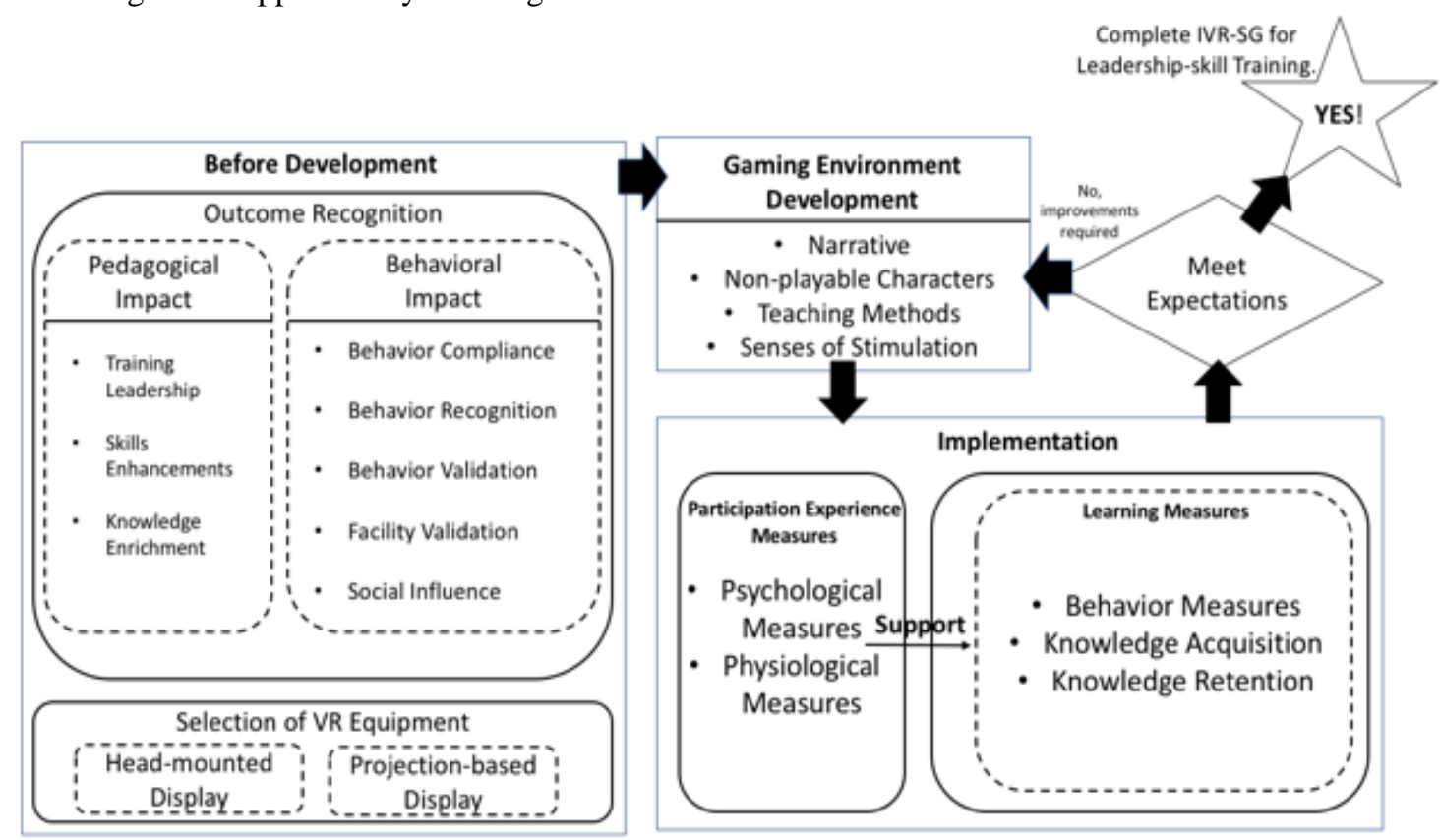

Fig 5 Conceptual Model for Developing and Implementing IVR-SG for Leadership Training

\section{CONCLUSION}

The study provided a systematic literature review on Immersive Virtual Reality - Serious Game (IVR-SG) for leadership training. Recent advancement of technology permits to predict an innovative teaching method in preparing professional for their progressing roles without putting the participants themselves at risk. The findings show the advantage along with disadvantage of IVR-SG in providing leadership knowledge and participants' behavior analysis. This study of systematic literature review offers in-depts understanding of the characteristics and configuration of IVR-SG, resulted in a conceptual framework for developing and implementing IVR-SG according to the examination into existing literatures. The conceptual framework is originated from findings of systematic literature review which aims contribute to future implementations of IVR-SG for leadership training. The authors found potential directions for future researches, particularly on the impact of different answers of navigation to overcome motion sickness. Hence, the future research on the application of an IVR-SG approach would be valuable as serious game ( $\mathrm{SG}$ ) could become a significant tool offering a safe, consistent and efficient learning experience in leadership training. 


\section{Serious Game for Leadership Skills in the Learning Organization Training}

\section{REFERENCES}

[1] Blanchard K. Leading at a higher level, revised and expanded edition: Blanchard on leadership and creating high performing organizations. FT Press; 2009 Sep 8.

[2] Cai Y, Goei SL, editors. Simulations, serious games and their applications. Springer Science \& Business Media; 2013 Nov 8.

[3] Chittaro L, Buttussi F. Assessing knowledge retention of an immersive serious game vs. a traditional education method in aviation safety. IEEE transactions on visualization and computer graphics. 2015 Jan 19;21(4):529-38.

[4] Connolly TM, Boyle EA, MacArthur E, Hainey T, Boyle JM. A systematic literature review of empirical evidence on computer games and serious games. Computers \& education. 2012 Sep 1;59(2):661-86.

[5] Cook DA, Levinson AJ, Garside S, Dupras DM, Erwin PJ, Montori VM. Instructional design variations in internet-based learning for health professions education: a systematic review and meta-analysis. Academic medicine. 2010 May 1;85(5):909-22.

[6] Zhang J, Issa RR. Collecting fire evacuation performance data using BIM-based immersive serious games for performance-based fire safety design. InComputing in Civil Engineering 20152015 (pp. 612-619).

[7] Krokos E, Plaisant C, Varshney A. Virtual memory palaces: immersion aids recall. Virtual Reality. 2019 Mar 5;23(1):1-5.

[8] Lovreglio R, Gonzalez V, Amor R, Spearpoint M, Thomas J, Trotter M, Sacks R. The need for enhancing earthquake evacuee safety by using virtual reality serious games. InLean \& Computing in Construction Congress 2017 Jul 4 (pp. 1-9)

[9] Lavalle SM. VIRTUAL REALITY.(2017).

[10] Lovreglio R, Gonzalez V, Feng Z, Amor R, Spearpoint M, Thomas J, Trotter M, Sacks R. Prototyping virtual reality serious games for building earthquake preparedness: The Auckland City Hospital case study. Advanced Engineering Informatics. 2018 Oct 1;38:670-82.

[11] Mitchell A, Savill-Smith C. The use of computer and video games for learning: A review of the literature.

[12] Navarro A, Pradilla JV, Madriñan P. Work in progress-Serious 3D game for mobile networks planning. In2010 IEEE Frontiers in Education Conference (FIE) 2010 Oct 27 (pp. T1F-1). IEEE.

[13] Rüppel U, Schatz K. Designing a BIM-based serious game for fire safety evacuation simulations. Advanced engineering informatics. 2011 Oct 1;25(4):600-11.

[14] Weber M. The theory of social and economic organization. Simon and Schuster; 2009 Nov 24.

[15] Shafritz JM, Ott JS, Jang YS. Classics of organization theory. Cengage Learning; 2015 Jan 6.

[16] Burns JM. Transactional and transforming leadership. Leading organizations. 1998 Sep 25;5(3):133-4.

\section{Authors Profile}

Basuki Wibawa is affiliated with National University of Jakarta as a Professor. The research interests include Technology based learning, Blended learning in educational field.

Pramis B.Wibawa is an MS scholar at University of Brawijaya. Has a bachelors degree in Business Administration and International Marketing and Business. The research interests span over business, Marketing and Corporate Strategic planning. 